\title{
Prognostic effect of preoperative serum estradiol level in postmenopausal breast cancer
}

Ju-Yeon Kim', Wonshik Han², Hyeong-Gon Moon², Soo Kyung Ahn², Jisun Kim², Jun Woo Lee², Min Kyoon Kim², Taeryung Kim ${ }^{3}$ and Dong-Young Noh ${ }^{2}$

\begin{abstract}
Background: The prognostic role of serum estrogen level in breast cancer patients is unclear. We investigated the prognostic importance of preoperative serum estradiol (E2) level in postmenopausal women according to their estrogen receptor (ER) status.

Methods: The medical records of 313 postmenopausal breast cancer patients who underwent surgery between 2006 and 2008 at a single institution were retrospectively evaluated. Patients who received neoadjuvant chemotherapy, synchronous bilateral breast cancer, or those with metastasis at diagnosis were excluded. Serum E2 and follicular stimulating hormone (FSH) levels were measured by radioimmunoassay and immunoradiometric assay, respectively, within 3 months prior to surgery. After a median follow-up of 52.0 months (11-77 months), 21 women were found to have metastatic disease.

Results: The overall, median E2 level was $13.0 \mathrm{pg} / \mathrm{ml}$, and was slightly higher in ER-positive than ER-negative $(p=0.69)$. The mean serum E2 level was significantly higher in patients with metastasis $(17.41 \pm 8.34 \mathrm{pg} / \mathrm{ml})$ than in those without metastasis $(13.54 \pm 7.58 \mathrm{pg} / \mathrm{ml})(\mathrm{p}=0.02)$. Kaplan-Meier analysis using a cut-off of $13 \mathrm{pg} / \mathrm{ml}$ showed that, ER negative $(p=0.02)$ but not ER positive $(p>0.05)$ patients with higher E2 level showed significantly poorer metastasis-free survival. Multivariate analysis showed that, the high E2 level of ER negative tumors was an independent negative prognostic factor for metastasis- free survival $(\mathrm{HR}, 3.32 ; 95 \% \mathrm{Cl}, 1.05$ to $10.51 ; \mathrm{p}=0.04)$.
\end{abstract}

Conclusions: Higher preoperative serum E2 level had a negative prognostic effect in postmenopausal women with breast cancer, especially in the ER-negative subgroup.

Keywords: Estradiol, Postmenopause, Metastasis, Survival

\section{Background}

Many epidemiologic and experimental studies support an association between higher serum levels of sex steroid hormones and an increased risk of postmenopausal breast cancer, especially for estrogen receptor (ER)-positive breast cancers [1-6]. However, the prognostic role of the serum level of these hormones in newly diagnosed breast cancer patients is still unclear. Although several studies have reported that higher serum testosterone levels at diagnosis were associated with poor prognosis in postmenopausal women with breast cancer, other studies demonstrated no such association [7-9]. The role

\footnotetext{
* Correspondence: hanw@snu.ac.kr

${ }^{2}$ Department of Surgery and Cancer Research Institute, Seoul National University College of Medicine, 28 Yongon-dong, Seoul 110-744, Korea Full list of author information is available at the end of the article
}

of testosterone in breast cancer has been attributed to its conversion to estrogen by aromatase.

Estrogen has been found to contribute significantly to breast tumor formation and growth [10-13]. High serum estradiol levels were reported to be associated with specific gene expression patterns in breast cancer tissue. [14]. In estrogen-dependent tumors, estrogen promotes cell proliferation and, suppresses apoptosis, by directly modulating gene transcription, making estrogen an important target in treatment [15].

ER status is important in breast cancer carcinogenesis and progression. Circulating estrogen binds to ER in breast cancer cells and stimulates cell division and growth. However, recent studies provided further molecular insights into the estradiol-dependent breast

\section{Biomed Central}

(C) 2013 Kim et al.; licensee BioMed Central Ltd. This is an open access article distributed under the terms of the Creative Commons Attribution License (http://creativecommons.org/licenses/by/2.0), which permits unrestricted use, distribution, and reproduction in any medium, provided the original work is properly cited. 
carcinogenesis, finding that estradiol may act independently of ER [16-18].

Serum estradiol level is significantly lower in postmenopausal than in premenopausal women. And postmenopausal women have been consistent in E2 levels without variation according to menstrual cycle. Here, we report the results of a single-institutional retrospective analysis of the prognostic importance of preoperative serum estradiol level in postmenopausal breast cancer patients. Our hypothesis is that serum estradiol level may be significant prognostic factor in postmenopausal breast cancer.

\section{Methods}

The Seoul national university hospital breast care center database was reviewed for the medical records of postmenopausal women who underwent curative surgery between September 2006 and December 2008 for newly diagnosed invasive breast cancer and for whom we had the information on serum estradiol levels within 3 months prior to surgery. Patients who received neoadjuvant chemotherapy, synchronous bilateral breast cancer or those with metastasis at diagnosis time were excluded from the study. Women were defined as postmenopausal if they had a bilateral oophorectomy, were aged 60 years or older, or were aged under 60 years with amenorrhea for at least 12 months, and their serum follicular stimulating hormone (FSH) levels satisfied the diagnostic criteria for menopause (FSH $>30 \mathrm{mIU} / \mathrm{mL}$ ). We identified 313 postmenopausal women eligible for the study (Figure 1).

Serum levels of E2 were measured by radioimmunoassay (RIA) using commercial kits (Biosource, Nivelles, Belgium), with intra- and inter-assay coefficients of variation $(\mathrm{CV})$ of $4.9 \%$ and $5.2 \%$, respectively. FSH were measured by immunoradiometric assay (IRMA) using commercial kits (Biosource), with a detection limit of $0.1 \mathrm{mlU} / \mathrm{mL}$, and intra- and inter assay CVs of $3.3 \%$ and $7.1 \%$, respectively.

Pathology data, including tumor size, grade, lymph node involvement, and immunohistochemistry results on hormone receptors expression, were reviewed. A cut-off value of $1 \%$ or more positively stained nuclei in the high-power fields was used to define ER and PR positivity. Patients were recommended to undergo adjuvant therapy and surveillance according to the St Gallen and/or NCCN guidelines.

Distant metastasis excluded local breast recurrence, axillary lymph node recurrence and newly diagnosed contralateral breast cancer. The time of metastasis was defined as the date confirmed by biopsy or image finding. Metastasis-free survival defined as the time period from the date of breast surgery to that of first diagnosis with distant metastasis by biopsy results or image or last

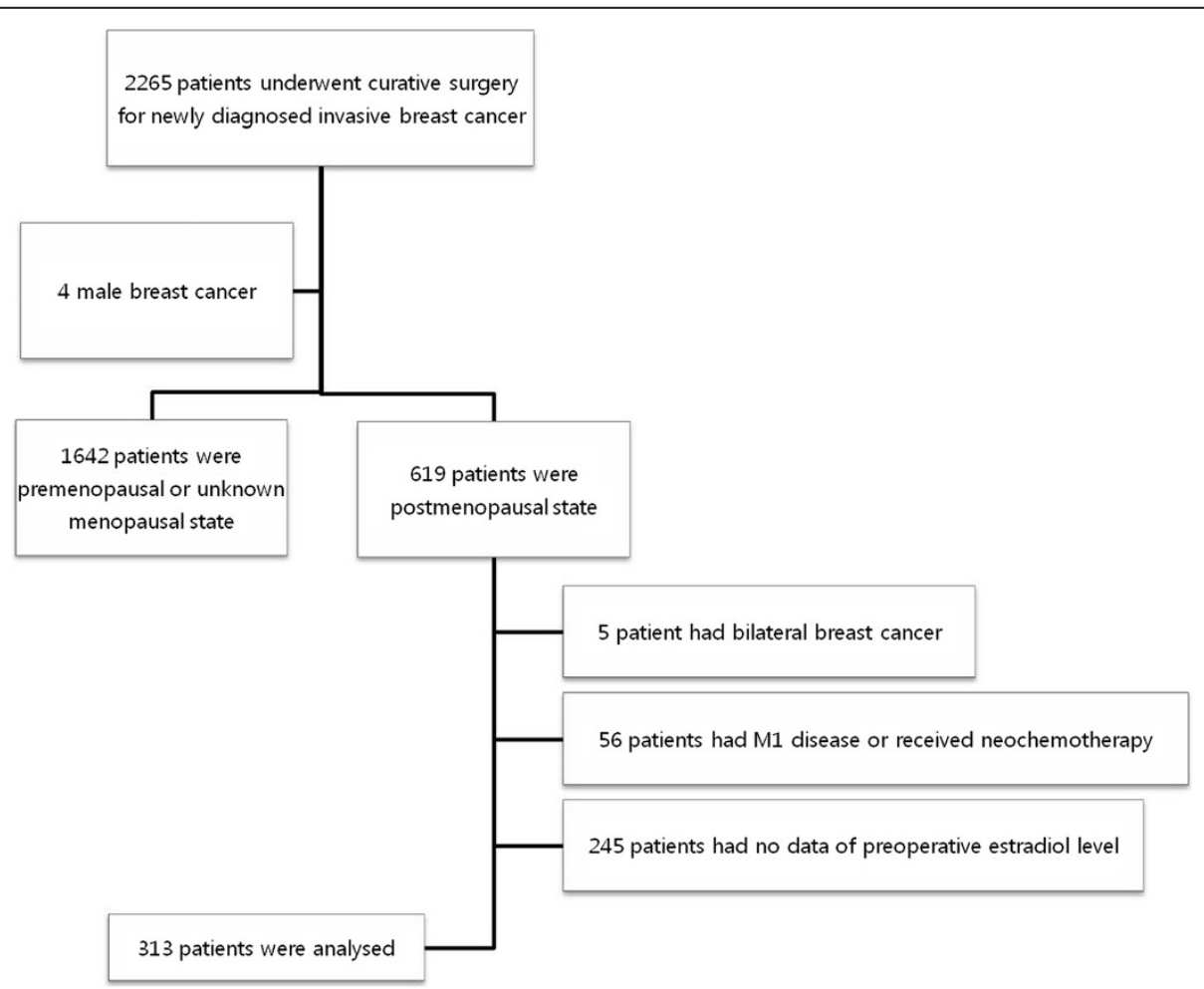

Figure 1 Flow chart of patients' selection. 
follow-up. The Cox regression model was utilized to identify significant independent factors related to distant metastasis.

Student's t-tests were used to compare E2 levels in two groups, and Pearson's correlation test was used to test the relationships between E2 level and age and body mass index (BMI). The Kaplan-Meier method and log-rank test were used for survival analysis. The Cox regression model was utilized to identify significant independent factors related to distant metastasis. The variables included in the final model were defined by backward selection. We excluded the missing or unknown data when we performed statistical analysis. Significance was defined as $p<0.05$. All statistical analyses were performed using SPSS (version 19.0 SPSS Inc., Chicago, IL, USA). Written informed consent was taken prior to surgery in all patients and the study protocol including the use of the database was approved by the Institutional Review Board of Seoul National University Hospital and met the guidelines of the responsible governmental agencies.

\section{Results}

The clinical and histopathological characteristics of the studied patients are listed in Table 1. Patients ranged in age from 45 to 83 years, with 3 patients having undergone bilateral oophorectomy before diagnosis of breast cancer. Of the 195 patients with ER or PR positive tumors, 192 received adjuvant hormonal therapy.

The overall median level of estradiol was $13.0 \mathrm{pg} / \mathrm{ml}$, with mean estradiol levels higher in patients with ER positive than ER negative tumors $(14.36 \pm 7.85 \mathrm{pg} / \mathrm{ml} v s$. $12.97 \pm 7.37 \mathrm{pg} / \mathrm{ml}, \mathrm{p}=0.69$ ) (Table 2). Serum levels of estradiol did not correlate with age (Pearson correlation coefficient $=0.033, p=0.56$ ) or BMI (Pearson correlation coefficient $=0.106, p=0.06$ ).

During a median follow-up time of 52.0 months after diagnosis (range, 11 to 77 months), 3 patients had locoregioanl recurrence, 2 patients had contralateral breast cancer, and 21 patients had distant metastasis as the first event. And one patient with local recurrence eventually had distant metastasis. As the results, 22 patients were diagnosed with distant metastases, 7 in the ER positive and 15 in the ER negative group. Mean serum estradiol level was significantly higher in patients with than without metastasis $(17.41 \pm 8.34 \mathrm{pg} / \mathrm{ml}$ vs. $13.54 \pm 7.58 \mathrm{pg} / \mathrm{ml}$, $p=0.02$ ).

We performed Kaplan-Meier survival analysis to evaluate the prognostic effect of estradiol according to ER status. Using the cut-off values $13 \mathrm{pg} / \mathrm{ml}$, which is the median value in this study, we found that metastasis free survival was lower in ER-positive patients with higher than with lower estradiol level, although the difference was not statistically significant (Figure 2a). In ER negative
Table 1 The clinical and histopathological characteristics of the included patients

\begin{tabular}{|c|c|c|c|c|}
\hline \multirow[t]{2}{*}{ Characteristics } & \multicolumn{4}{|c|}{ Number of patients (\% of total) } \\
\hline & Total & ER positive & ER negative & $P$ value \\
\hline Enrolled patients & 313 & 190 & 123 & \\
\hline Tumor size (mean), cm & 2.17 & 2.03 & 2.40 & \\
\hline$<2$ & 170 & $121(63.7 \%)$ & 49(39.8\%) & $<0.001$ \\
\hline $2-5$ & 138 & $65(34.2 \%)$ & $73(59.3 \%)$ & \\
\hline$\geq 5$ & 5 & $4(2.1 \%)$ & $1(0.8 \%)$ & \\
\hline \multicolumn{5}{|l|}{ Nodal status } \\
\hline 0 & 206 & $130(68.4 \%)$ & $76(61.8 \%)$ & 0.310 \\
\hline $1-3$ & 81 & $44(23.2 \%)$ & $37(30.1 \%)$ & \\
\hline $4-9$ & 14 & $7(3.7 \%)$ & $7(5.7 \%)$ & \\
\hline$\geq 10$ & 12 & $9(4.7 \%)$ & $3(2.4 \%)$ & \\
\hline Nuclear grade & & & & $<0.001$ \\
\hline Grade 1 or 2 & 127 & 109(57.4\%) & 18(14.6\%) & \\
\hline Grade 3 & 175 & $76(40.0 \%)$ & $99(80.5 \%)$ & \\
\hline Unknown & 11 & $5(2.6 \%)$ & $6(4.9 \%)$ & \\
\hline Histologic grade & & & & $<0.001$ \\
\hline Grade 1 or 2 & 131 & $113(59.5 \%)$ & 18(14.6\%) & \\
\hline Grade 3 & 153 & $59(31.0 \%)$ & $94(76.4 \%)$ & \\
\hline Unknown & 29 & $18(9.5 \%)$ & $11(9.0 \%)$ & \\
\hline PR status & & & & $<0.001$ \\
\hline Positive & 133 & $128(67.4 \%)$ & $5(4.1 \%)$ & \\
\hline Negative & 180 & $62(32.6 \%)$ & 118(95.9\%) & \\
\hline HER2/neu status & & & & $<0.001$ \\
\hline Positive & 45 & $9(4.7 \%)$ & $36(29.3 \%)$ & \\
\hline Negative & 246 & $170(89.5 \%)$ & $76(61.8 \%)$ & \\
\hline Unknown & 22 & $11(5.8 \%)$ & $11(8.9 \%)$ & \\
\hline Operation & & & & 0.014 \\
\hline Conservation & 175 & $117(61.6 \%)$ & $58(47.2 \%)$ & \\
\hline Mastectomy & 138 & 73(38.4\%) & $65(52.8 \%)$ & \\
\hline Adjuvant chemotherapy & & & & $<0.001$ \\
\hline No & 131 & $103(54.2 \%)$ & $28(22.8 \%)$ & \\
\hline Yes & 182 & $87(45.8 \%)$ & $95(77.2 \%)$ & \\
\hline Adjuvant Radiotherapy & & & & 0.129 \\
\hline No & 133 & $74(38.9 \%)$ & $59(48.0 \%)$ & \\
\hline Yes & 180 & $116(61.1 \%)$ & $64(52.0 \%)$ & \\
\hline \multicolumn{5}{|l|}{ Adjuvant hormonal therapy } \\
\hline No & & $3(1.6 \%)$ & & \\
\hline SERM & & $36(18.9 \%)$ & & \\
\hline $\mathrm{Al}$ & & 137(72.1\%) & & \\
\hline Switch* & & $14(7.4 \%)$ & & \\
\hline Distant metastasis & & $7(3.7 \%)$ & $15(12.2 \%)$ & 0.006 \\
\hline
\end{tabular}

Abbreviations: ER estrogen receptor, $P R$ Progesterone receptor, SERM selective estrogen modulator, $A l$ aromatase inhibitor. Switch*: Tamoxifen for 2-3 year, and then aromatase inhibitor to complete 5 year. 
Table 2 Mean estradiol levels according to subgroups

\begin{tabular}{llll}
\hline & & $\begin{array}{l}\text { Estradiol level } \\
\text { (Mean } \pm \text { SD, pg/mL) }\end{array}$ & p value \\
\hline Tumor size & $<2 \mathrm{~cm}$ & $13.69 \pm 7.17$ & 0.75 \\
& $\geq 2 \mathrm{~cm}$ & $13.97 \pm 8.28$ & \\
Nodal status & N0 & $13.93 \pm 7.99$ & 0.71 \\
& N1-3 & $13.59 \pm 7.09$ & \\
ER & Negative & $12.97 \pm 7.37$ & 0.69 \\
& Positive & $14.36 \pm 7.85$ & \\
PR & Negative & $13.41 \pm 7.52$ & 0.27 \\
& Positive & $14.37 \pm 7.89$ & 0.81 \\
Her-2 & Negative & $14.09 \pm 7.80$ & \\
& Positive & $14.40 \pm 7.33$ & 0.80 \\
Histologic grade & Grade 1 or 2 & $13.91 \pm 8.05$ & \\
& Grade 3 & $13.68 \pm 7.25$ & 0.89 \\
Nuclear grade & Grade 1 or 2 & $13.78 \pm 8.38$ & \\
& Grade 3 & $13.90 \pm 7.11$ &
\end{tabular}

Abbreviations: SD Standard deviation, $E R$ estrogen receptor, $P R$ Progesterone receptor.

patients, higher estradiol levels were significantly associated with increased risk of metastasis (Log-rank=0.02) (Figure 2b).

To confirm the prognostic effect of serum estradiol in ER negative breast cancer patients, we performed a multivariate analysis using a Cox hazard model. The estradiol level was found to be an independent negative prognostic indicator of metastasis free survival (HR, 3.32; 95\% CI, 1.05 to $10.51 ; \mathrm{p}=0.04$ ) (Table 3).

We also found that, ER negative patients with higher estradiol levels were significantly associated with increased risk of diasease-sepecific events (including locoregional recurrence and contralateral recurrence). (Log rank=0.034) In multivariate analysis using a Cox hazard model, high E2 ( $>13 \mathrm{pg} / \mathrm{ml})$ of ER negative tumors was negative prognostic factor for disease-free survival (HR, 2.717), but the p value was 0.058 .

\section{Discussion}

We have shown here that higher serum estrogen levels contribute to the risk of distant metastasis in postmenopausal breast cancer patients with ER negative tumors. Rock et al. [7] have also shown the significant association between serum estradiol level and patient's survival in a nested case-control cohort of a randomized trial of diet intervention (Women's Health Eating and Living study), although that study did not include subgroup analysis based on ER expression status.

Our observation, that serum estradiol level affects prognosis only in patients with ER negative tumors, was interesting since estradiol is thought to play a key role in the carcinogenesis of ER positive tumors. Indeed, our findings are supported by recent experimental studies showing that estradiol regulates the progression of ER negative breast cancer cell lines. For example, Gupta et al. [16] reported that estrogen promotes the growth, stromalization, and angiogenesis of an ER negative breast cancer cell line by systemic induction of host angiogenesis and bone marrow-derived stromal cell recruitment. Similarly, Banka et al. [17] showed that estradiol treatment of ovariectomized mice injected with an ER negative mouse mammary carcinoma cell line markedly increased the incidence of lung metastasis. These studies suggest that estradiol can act as a potent metastasis-promoter in ER negative tumors by a novel mechanism involving the host microenvironment. And another plausible explanation
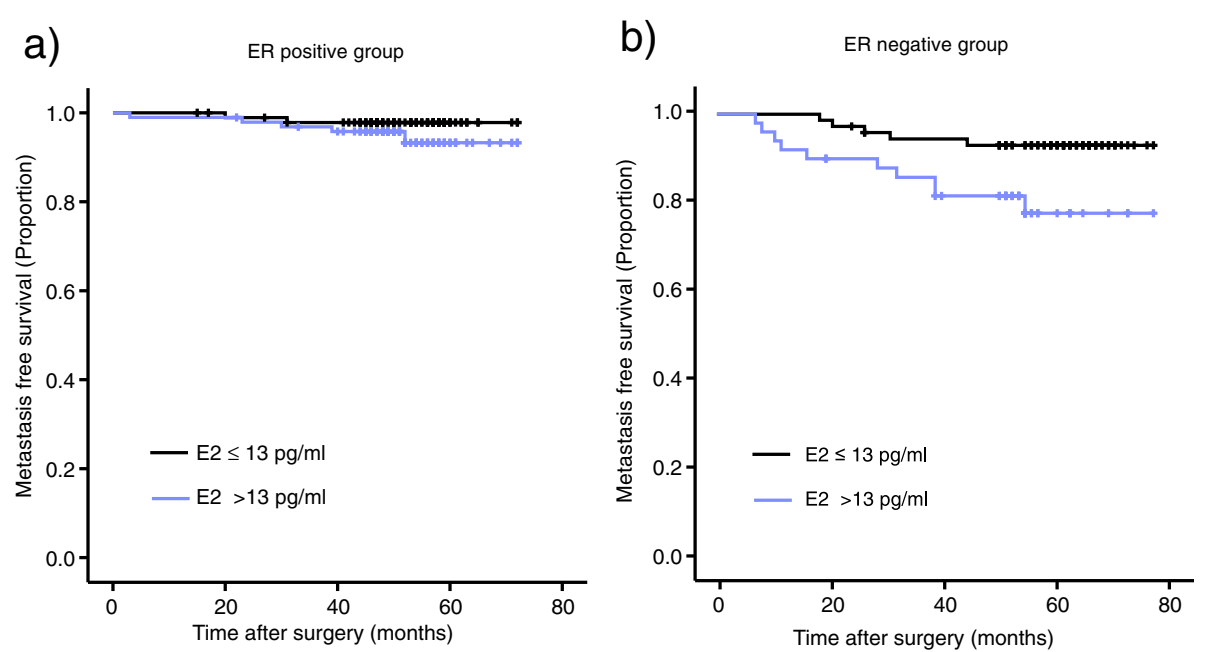

Figure 2 Metastasis-free survivals according to ER status. a. Metastasis-free survival was lower in ER-positive patients with higher than with lower estradiol level, although the difference was not statistically significant (Log-rank=0.25). b. In ER negative patients, higher estradiol levels were significantly associated with increased risk of metastasis (Log-rank=0.02). 
Table 3 Univariate and multivariate analyses of prognostic factors including serum E2 level for metastasis-free survival according to ER status

\begin{tabular}{|c|c|c|c|c|c|c|c|c|c|c|c|c|}
\hline & \multicolumn{6}{|c|}{ ER positive group } & \multicolumn{6}{|c|}{ ER negative group } \\
\hline & \multicolumn{3}{|c|}{ Univariate analysis } & \multicolumn{3}{|c|}{ Multivariate analysis } & \multicolumn{3}{|c|}{ Univariate analysis } & \multicolumn{3}{|c|}{ Multivariate analysis } \\
\hline & $\mathrm{HR}$ & $95 \% \mathrm{Cl}$ & $p$ value & $\mathrm{HR}$ & $95 \% \mathrm{Cl}$ & $p$ value & $\mathrm{HR}$ & $95 \% \mathrm{Cl}$ & $\mathrm{p}$ value & $\mathrm{HR}$ & $95 \% \mathrm{Cl}$ & $\mathrm{p}$ value \\
\hline Age & 1.06 & $0.97-1.16$ & 0.24 & & & & 1.02 & 0.95-1.09 & 0.63 & & & \\
\hline $\mathrm{BMl}, \geq 23 \mathrm{~kg} / \mathrm{m}^{2}$ & 1.22 & $0.52-2.86$ & 0.64 & & & & 1.02 & $0.37-2.82$ & 0.97 & & & \\
\hline HER2/neu positive & 0.99 & $0.98-1.01$ & 0.69 & & & & 0.97 & $0.33-2.84$ & 0.96 & & & \\
\hline Tumor size, $>2 \mathrm{~cm}$ & 10.65 & $1.28-88.48$ & 0.03 & 3.75 & $0.41-33.98$ & 0.24 & 4.75 & $1.07-21.06$ & 0.04 & 1.85 & $0.37-9.27$ & 0.45 \\
\hline \multicolumn{13}{|l|}{ Node metastasis } \\
\hline 0 & Ref. & & & Ref. & & & Ref. & & & & & \\
\hline $1-3$ & 1.47 & $0.13-16.25$ & 0.75 & 1.12 & $0.10-12.66$ & 0.93 & 4.00 & $1.17-13.70$ & 0.03 & 2.45 & $0.65-9.31$ & 0.19 \\
\hline$>3$ & 18.96 & $3.47-103.63$ & 0.001 & 9.05 & $1.50-54.45$ & 0.02 & 10.70 & $2.67-42.90$ & 0.001 & 2.99 & $0.62-14.36$ & 0.17 \\
\hline Nuclear grade 3 & 3.06 & $1.06-8.83$ & 0.04 & 1.21 & $0.08-19.62$ & 0.87 & 1.11 & $0.53-2.34$ & 0.78 & & & \\
\hline Histologic grade 3 & 3.59 & $1.24-10.38$ & 0.02 & 8.04 & $0.54-120.81$ & 0.13 & 1.16 & $0.55-2.45$ & 0.69 & & & \\
\hline ELTE & 2.91 & $0.65-13.00$ & 0.16 & & & & 8.28 & $2.63-26.06$ & $<0.001$ & 4.24 & $1.18-15.18$ & 0.03 \\
\hline E2 level, $>13 \mathrm{pg} / \mathrm{ml}$ & 2.54 & $0.49-13.13$ & 0.27 & & & & 3.373 & $1.07-10.61$ & 0.04 & 3.32 & $1.05-10.51$ & 0.04 \\
\hline Chemotherapy & 2.49 & $0.92-6.75$ & 0.07 & & & & & & & & & \\
\hline
\end{tabular}

A multivariate analysis was set by using all of the predictors with $p$ values under 0.05 in univariate analysis.

Abbreviations: ER estrogen receptor, BMI Body mass index, ELTE endolymphatic tumor emboli, E2 Estradiol.

might be possibility that more aggressive ER negative breast tumors are associated with higher estrogen levels because they share a common cause, for example, such tumors could elicit a strong inflammatory response which both enables metastasis and also upregulates aromatase activity in surrounding tissues.

Indirect evidence supporting the role of estradiol in ER negative tumor development can also be found in human clinical studies. Ovariectomy was shown to signicantly reduce the incidence of both ER negative and ER positive tumors $[19,20]$. Prophylactic oophorectomy can prevent the development of breast cancers in BRCA1 mutation carriers in whom the main types of breast cancer are ER negative [21-23]. However, it is unclear whether it may be the consequence of inhibition of the transition of luminal of ER positive cells to negative or inhibition of tumorigenesis itself. And among BRCA1 mutation carriers older than age 50, no risk reduction was evident with prophylactic oophorectomy [23]. It is also unclear whether the estrogen lowering treatments like aromatase inhibitors were effective in ER negative tumors. According to the study of Jones et al. [24] which was central review of pathological specimens from patients entered in BIG 1-98 trials, aromatase inhibitors might have advantage in only patients whose tumor express ER. However, they didn't measure the preoperative estradiol level, so it was impossible to compare the difference of effect according to estradiol level in patients with ER negative or positive tumors.

It is unclear why serum estradiol level was not significantly associated with the development of metastasis in
ER positive breast cancer patients. One possible explanation is that almost all patients with ER positive tumors in our study cohort (98.4\%) received anti-estrogen treatment with either tamoxifen or aromatase inhibitors. In addition, there were fewer events in ER positive tumors, so it might act as cause of limited power.

Premenopausal women experience changes in their serum estrogen levels throughout their menstrual cycles. In contrast, postmenopausal women have been more consistent in E2 levels, because of the absence of the variability of hormone levels with the menstrual cycle. Therefore, to analysis the difference of prognosis according to serum E2 level in premenopausal women, constant measure of E2 in time is important.

This study has several limitations. Due to its retrospective nature, there may have been a selection bias. Specially, the measurement of estradiol levels was not performed as a part of the prospective design. Some were measured for other studies, and others measured for standard element of the work-up for breast cancer by special physicians during different periods. Also, the median follow-up period of 52 months was not sufficient to assess the prognostic effect in breast cancer patients, especially in patients with ER positive tumors. And our findings are based on a quite small number of cases. Further confirmatory studies are needed.

\section{Conclusions}

We found that a higher level of serum estradiol had a negative prognostic effect in postmenopausal women with ER negative breast cancer. These findings are hypothesis 
generating, suggesting that an estrogen-rich microenvironment can facilitate the progression of ER negative tumors. Additional in vivo and prospective cohort studies are needed to address this hypothesis.

\section{Abbreviations}

ER: Estrogen receptor; E2: Estradiol; FSH: Follicular stimulating hormone; RIA: Radioimmunoassay; CV: Coefficients of variation; IRMA: Immunoradiometric assay; BMI: Body mass index.

\section{Competing interests}

The authors declare that they have no competing interests.

\section{Authors' contributions}

All the authors have made substantial contributions to conception and design, acquisition of data, or analysis and interpretation of data. JYK conceived of and organized the study and was primarily responsible for drafting the manuscript. SKA and JK carried out collection of primary data and provided clinical input. JWL, MKK and TK confirmed patients' outcomes of recurrence and follow up results and guided statistical analysus. HGM and NDY participated in the study design and helped to draft the manuscript. As responding author, $\mathrm{WH}$ designed and coordinated the research and provided close guidance throughout the process. All authors read and approved the final manuscript. The authors have been involved in drafting the manuscript or revising it critically for important intellectual content and have all given final approval of the version to be published.

\section{Author details}

${ }^{1}$ Department of Surgery, Gyeongsang National University Hospital, 90 Chilamdong, Jinju, Korea. ${ }^{2}$ Department of Surgery and Cancer Research Institute, Seoul National University College of Medicine, 28 Yongon-dong, Seoul 110-744, Korea. ${ }^{3}$ Department of Surgery, Gachon University Gil Hospital, 1198, Guwol-Dong, Incheon 405-760, Korea.

Received: 19 July 2013 Accepted: 23 October 2013 Published: 27 October 2013

\section{References}

1. Cummings SR, Lee JS, Lui LY, Stone K, Ljung BM, Cauleys JA: Sex hormones, risk factors, and risk of estrogen receptor-positive breast cancer in older women: a long-term prospective study. Cancer Epidemiol Biomarkers Prev 2005, 14:1047-1051.

2. Key T, Appleby P, Barnes I, Reeves G: Endogenous sex hormones and breast cancer in postmenopausal women: reanalysis of nine prospective studies. J Natl Cancer Inst 2002, 17:606-616.

3. Cummings SR, Tice JA, Bauer S, Browner WS, Cuzick J, Ziv E, et al: Prevention of breast cancer in postmenopausal women: approaches to estimating and reducing risk. J Natl Cancer Inst 2009, 18:384-398.

4. Sieri S, Krogh V, Bolelli G, Abagnato CA, Grioni S, Pala V, et al: Sex hormone levels, breast cancer risk, and cancer receptor status in postmenopausal women: the ORDET cohort. Cancer Epidemiol Biomarkers Prev 2009, 18:169-176.

5. Missmer SA, Eliassen AH, Barbieri RL, Hankinson SE: Endogenous estrogen, androgen, and progesterone concentrations and breast cancer risk among postmenopausal women. J Natl Cancer Inst 2004, 15:1856-1865.

6. Kaaks R, Rinaldi S, Key TJ, Berrino F, Peeters PH, Biessy C, et al: Postmenopausal serum androgens, oestrogens and breast cancer risk: the European prospective investigation into cancer and nutrition. Endocr Relat Cancer 2005, 12:1071-1082.

7. Rock CL, Flatt SW, Laughlin GA, Gold EB, Thomson CA, Natarajan L, et al: Reproductive steroid hormones and recurrence-free survival in women with a history of breast cancer. Cancer Epidemiol Biomarkers Prev 2008, 17:614-620.

8. Berrino F, Pasanisi P, Bellati C, Venturelli E, Krogh V, Mastroianni A, et al: Serum testosterone levels and breast cancer recurrence. Int J Cancer 2005, 113:499-502.

9. Secreto G, Zumoff B: Paradoxical effects associated with supranormal urinary testosterone excretion in premenopausal women with breast cancer: increased risk of postmastectomy recurrence and higher remission rate after ovariectomy. Cancer Res 1983, 43:3408-3411.
10. Pike MC, Spicer DV, Dahmoush L, Press MF: Estrogens, progestogens, normal breast cell proliferation, and breast cancer risk. Epidemiol Rev 1993, 15:17-35.

11. Hulka BS: Epidemiology of susceptibility to breast cancer. Prog Clin Biol Res 1996, 395:159-174

12. Pathak DR, Osuch JR, He J: Breast carcinoma etiology: current knowledge and new insights into the effects of reproductive and hormonal risk factors in black and white populations. Cancer 2000, 1(5 Suppl):1230-1238.

13. Pike MC, Spicer DV: Hormonal contraception and chemoprevention of female cancers. Endocr Relat Cancer 2000, 7:73-83.

14. Haakensen VD, Bjoro T, Luders T, Riis M, Bukholm IK, Kristensen VN, et al: Serum estradiol levels associated with specific gene expression patterns in normal breast tissue and in breast carcinomas. BMC cancer 2011, 11:332

15. Katzenellenbogen BS, Katzenellenbogen JA: Estrogen receptor transcription and transactivation: Estrogen receptor alpha and estrogen receptor beta: regulation by selective estrogen receptor modulators and importance in breast cancer. Breast Cancer Res 2000, 2:335-344.

16. Gupta PB, Kuperwasser C: Contributions of estrogen to ER-negative breast tumor growth. J Steroid Biochem Mol Biol 2006, 102:71-78.

17. Banka CL, Lund CV, Nguyen MT, Pakchoian AJ, Mueller BM, Eliceiri BP: Estrogen induces lung metastasis through a host compartment-specific response. Cancer Res 2006, 1:3667-3672.

18. Gupta PB, Proia D, Cingoz O, Weremowicz J, Naber SP, Weinberg RA, et al: Systemic stromal effects of estrogen promote the growth of estrogen receptor-negative cancers. Cancer Res 2007, 1:2062-2071.

19. Early Breast Cancer Trialists' Collaborative Group: Systemic treatment of early breast cancer by hormonal, cytotoxic, or immune therapy. 133 randomised trials involving 31,000 recurrences and 24,000 deaths among 75,000 women. Lancet 1992, 11:71-85.

20. Nissen-Meyer R: Prophylactic endocrine treatment in carcinoma of the breast. Clin Radiol 1964, 15:152-160.

21. Rebbeck TR, Lynch HT, Neuhausen SL, Narod SA, Van't Veer L, Garber JE, et al: Prophylactic oophorectomy in carriers of BRCA1 or BRCA2 mutations. N Engl J Med 2002, 23:1616-1622.

22. Rebbeck TR, Kauff ND, Domchek SM: Meta-analysis of risk reduction estimates associated with risk-reducing salpingo-oophorectomy in BRCA1 or BRCA2 mutation carriers. I Natl Cancer Inst 2009, 101:80-87.

23. Eisen A, Lubinski J, Klijn J, Moller P, Lynch HT, Offit K, et al: Breast cancer risk following bilateral oophorectomy in BRCA1 and BRCA2 mutation carriers: an international case-control study. J Clin Oncol 2005, 23:7491-7496.

24. Viale G, Regan MM, Maiorano E, Mastropasqua MG, Dell'Orto P, Rasmussen $\mathrm{BB}$, et al: Prognostic and predictive value of centrally reviewed expression of estrogen and progesterone receptors in a randomized trial comparing letrozole and tamoxifen adjuvant therapy for postmenopausal early breast cancer: BIG 1-98. J Clin Oncol 2007, 25:3846-3852.

doi:10.1186/1471-2407-13-503

Cite this article as: Kim et al:: Prognostic effect of preoperative serum estradiol level in postmenopausal breast cancer. BMC Cancer 2013 13:503.

\section{Submit your next manuscript to BioMed Central and take full advantage of:}

- Convenient online submission

- Thorough peer review

- No space constraints or color figure charges

- Immediate publication on acceptance

- Inclusion in PubMed, CAS, Scopus and Google Scholar

- Research which is freely available for redistribution 